\title{
Preliminary molecular variability among haplotypes of Saudi Arabian house sparrow Passer domesticus
}

\author{
Sayed A. M. Amer ${ }^{1,2^{*}}$, Metwally M. Montaser ${ }^{1,3}$, Mohammed Shobrak ${ }^{1}$ \\ ${ }^{1}$ Faculty of Science, Taif University, Taif, Kingdom of Saudi Arabia; *Corresponding Author: yasser92us@yahoo.com \\ ${ }^{2}$ Department of Zoology, Faculty of Science, Cairo University, Giza, Egypt; \\ ${ }^{3}$ Department of Zoology, Faculty of Science, Al-Azhar University, Cairo, Egypt.
}

Received 22 September 2011; revised 20 October 2011; accepted 30 October 2011.

\begin{abstract}
Genetic variability of Passer domesticus from different localities of Saudi Arabia was investigated. Six hundred and fifty nine nucleotides were sequenced from the mitochondrial cytochrome b gene. There was a slight difference among the studied haplotypes and most substitutions were synonymous. In some haplotypes at the west of Arabian Peninsula (mountainous habitat), two transitions only were non-synonymous. The data were used to construct the relationship of the Arabian house sparrow to its con specific taxa from Europe and America. Neighbor-joining (NJ), maximum-parsimony (MP) and maximum-likelihood (ML) analytical methods were used. The three methods showed clustering of the Arabian haplotypes in one group and their sister relationship with the haplotypes from Netherlands and America. A spanish haplotype came basal to both groups. Collecting more samples and more DNA data could be of necessary to clearly address the genetic variability of this rapidly propagated species in Arabia.
\end{abstract}

Keywords: Saudi Arabia; House Sparrow; Mitochondrial DNA; Genetic Variability

\section{INTRODUCTION}

The house sparrow, Passer domesticus is distributed in Europe, North Africa and parts of Asia such as Middle East, Indian subcontinent and a narrowing band from northern Asia toward the Pacific coast. Its large-scale spread includes North and South America, South Africa, Australia and New Zealand [1-3].

The genetic diversity among the avian fauna is found to be low, probably due largely to the greater mobility of birds, resulting in higher levels of gene flow [4]. There have been several studies of the genetics of house sparrows on species and population level [5-11]. Moreover, the relationships among their congeneric species and to other finches (Passeridae and New World sparrows) have been tackled molecularly, for the first time, by Allende et al. [12]. Recently, the genetic relationships among passerines and other related families were studied using mitochondrial and nuclear genome's data [13]. Dor and Lotem [14] have studied the parentage of the house sparrows on a molecular basis.

Quantifying and characterizing avian genetic variability should be a priority in conservation to evaluate the effect of recent drastic population changes, to preserve present-day diversity and, eventually, to provide guidelines for future conservation plans [15]. Despite its close proximity to man, relatively little is known about the connectivity between house sparrow populations. Do the various sites that has been occupied by the species form a continuous population, or are we dealing with a more meta population type of population structure? These Conservation information should take into account knowledge on genetic population structure. Therefore the aim of the present study was to collect samples of the house sparrow from around the Kingdom of Saudi Arabia in order to sequence an orthologous gene from each of these samples. Such data could aid to understand the relatedness of these haplotypes and to get an overall picture of the genetic variability of this passerine bird providing guidelines for its conservation.

\section{MATERIALS AND METHODS}

We collected 17 samples of $P$. domesticus from the wild of 6 localities from Saudi Arabia (Arar, Qassim, Tabuk, Al-Madina, Taif and Jazan). See Figure 1 that explains the exact localities. Blood and tissue samples have been numbered and labeled immediately in the lab and preserved in $-80^{\circ} \mathrm{C}$ for further molecular studies. 


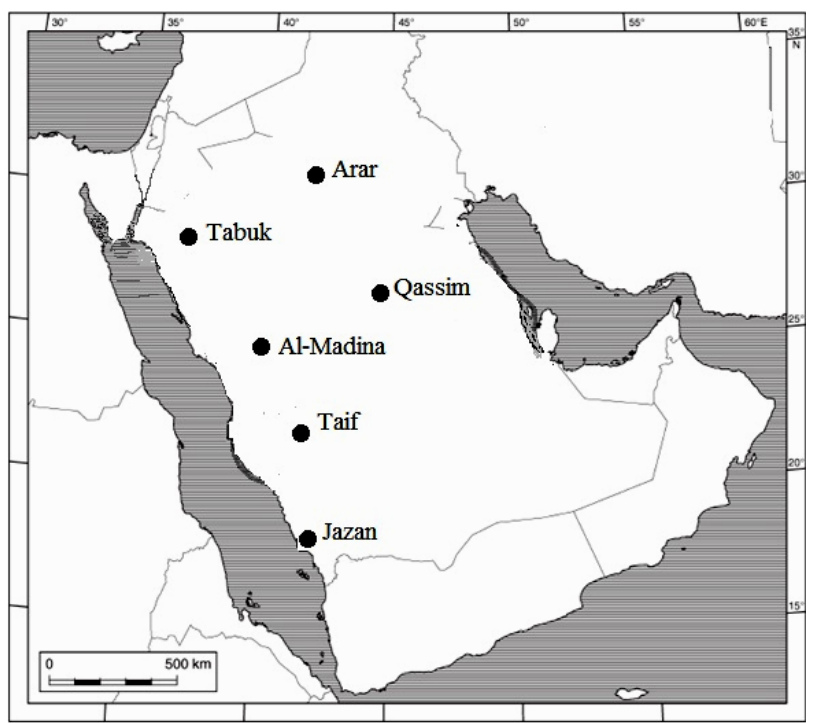

Figure 1. Map of the Arabian Peninsula showing the Saudi Arabian localities from which the studied samples have been collected.

DNA was extracted from $0.5 \mathrm{ml}$ blood samples with QIAGEN spin-column kits according to the manufacturer's instruction. Extracted DNA was spectrophotmetrically quantified at 260/280 $\mathrm{nm}$ and was used for polymerase chain reaction (PCR).

PCR was performed in $50 \mu \mathrm{l}$ total volume of reaction buffer containing $0.2 \mathrm{mM}$ dNTPs, $1.5 \mathrm{mM} \mathrm{MgCl}_{2}, 2 \mu \mathrm{l}$ of DNA solution and $0.25 \mathrm{U}$ of DNA Taq-polymerase (Invitrogen). $0.2 \mu \mathrm{M}$ of each of the L14841 5'-AAAAAGCTTCCATCCAACATCTCAGCATGATGAAA-3' and H 15767 5'-ATGAAGGGATGTTCTACTGGTTG-3' as detailed by Edwards et al. [16] were also added. The reaction mixture was put into a $0.2 \mathrm{ml}$ thin-walled PCR tube and amplification was performed in PXE 0.5 thermal cycler (Thermo Electron Corporation Co.) with the following profile: $94^{\circ} \mathrm{C}$ for $5 \mathrm{~min}$ followed by 30 cycles of $94^{\circ} \mathrm{C}$ for $1 \mathrm{~min}, 58^{\circ} \mathrm{C}$ for $1 \mathrm{~min}$ and $72^{\circ} \mathrm{C}$ for $1 \mathrm{~min}$. A final strand elongation at $72^{\circ} \mathrm{C}$ was done for an additional $7 \mathrm{~min}$.

The resultant solutions were electrophoresed on a $1.5 \%$ agarose gel in TAE ( $40 \mathrm{mM}$ Tris, $40 \mathrm{mM}$ acetic acid and $1 \mathrm{mM}$ ethylenediamine-tetra acetic acid) and the gels were stained with ethidium bromide. 100 bp DNA Ladder (Biolabs) was used as a marker for the molecular weight size. The PCR products were then purified from gel with the use of spin column according to the Kit Manual.

Sequencing reactions were performed in a MJ Research PTC-225 Peltier Thermal Cycler using a ABI PRISM. BigDyeTM Terminator Cycle Sequencing Kits with AmpliTaq-DNA polymerase (FS enzyme) (Applied Biosystems) following the protocols supplied by the ma- nufacturer were used. A single-pass sequencing was performed on each template using the last mentioned PCRprimers. The fluorescent-labeled fragments were purified from the unincorporated terminators with an ethanol precipitation protocol. The samples were resuspended in distilled water and subjected to electrophoresis in an ABI 3730xl sequencer (Applied Biosystems).

Nucleotide sequences of the mitochondrial cytb gene (659 bp) were aligned with the same fragment for other haplotypes from the DDBJ database (1 from USA, 1 from Netherlands, 1 from Spain, $1 P$. flaveolus and 1 from $P$. luteus). One additional outgroup taxan (Petronia petronia) was included in the alignment in order to root the tree. The alignment was carried out by using the DNASIS 3.5 (Hitachi) and MacClade 4.03 (Sinauer Associates, Inc.) with manual adjustments. We conducted the tree analyses by neighbor-joining (NJ), maximumparsimony (MP) and maximum-likelihood (ML) methods. These analyses were done in PAUP* 4.0b10 [17] by heuristic searches with the TBR branch swapping, 10 random taxon additions and 1000 bootstrap replications for each method. Juckes-Cantor distance model was used to construct a neighbor-joining tree [18].

\section{RESULTS AND DISCUSSION}

Unambiguous 659 sites from cytb gene for 17 samples of the house sparrow $P$. domesticus were sequenced in this study. These data were deposited in DDBJ/EMBL GenBank database with their accession numbers (AB671331-AB671347). The sequences were aligned and were used for analysis. These data showed base frequencies of $\mathrm{A}$ $=29.3 \%, \mathrm{C}=35.1 \%, \mathrm{G}=12.8 \%$ and $\mathrm{T}=22.8 \%$. Of these nucleotides, 558 were constant and 101 were variables. Sixty seven of the variable sites were parsimony-uninformative and 34 were informative under parsimony criterion. The estimated uncorrected pair wise distance (Table 1) was zero among the different Saudi Arabian haplotypes except those from Jazan, which showed very low distance to other Arabian haplotypes $(\mathrm{D}=0.002$ ). Jazan and other Arabian individuals showed close distance to both American and Netherlands haplotypes. A Spanish haplotype was equally distant from other Arabians, Netherlands and American individuals $(\mathrm{D}=0.006)$ and more distant from Jazan haplotype $(\mathrm{D}=0.008)$. Figure 2 depicts an $\mathrm{NJ}$ tree that has been constructed using the aligned sequences and Neighbor-joining algorithm [18] with Juckes-Cantor. Similar topology was obtained by maximum-parsimony under similar conditions. An optimal ML tree was also found with similar topology and a negative log likelihood of 1369.479. The three analytical methods (NJ, MP and ML) showed the homogeneity of the house sparrows globally (bootstrap = 100, 100, 99, respectively) and clustering of the Arabian 
Table 1. Uncorrected pair wise distances determined between haplotypes from different localities. "Others” refer to all Saudi Arabian haplotypes except those from Jazan since they showed zero distance when they compared.

\begin{tabular}{ccccc}
\hline & Other localities & Jazan & USA & Netherlands \\
\hline Other localities & - & & & \\
Jazan & 0.002 & - & & \\
USA & 0.003 & 0.005 & - & \\
Netherlands & 0.003 & 0.005 & 0.000 & - \\
Spain & 0.006 & 0.008 & 0.006 & 0.006 \\
\hline
\end{tabular}

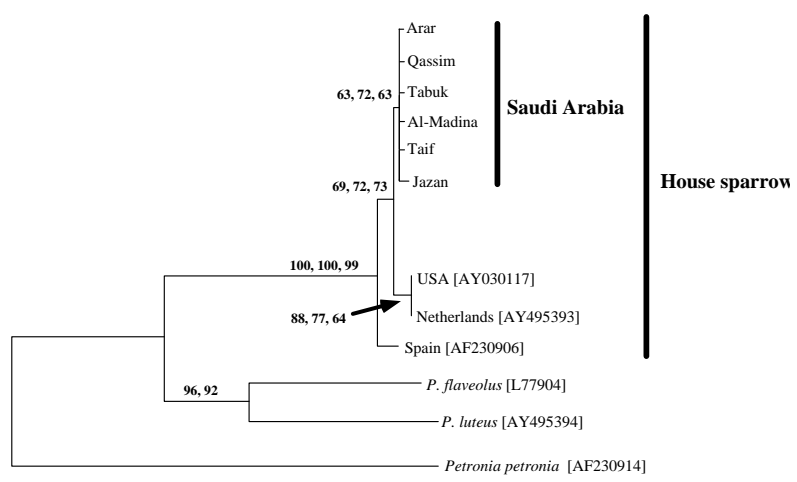

- 0.005 substitutions/site

Figure 2. Neighbor-joining tree constructed from 659 bp of cytb gene among the different studied haplotypes. The bootstrap values are showed at nodes for neighbor-joining, maximum-parsimony and maximum-likelihood methods, respectively, when they are more than $50 \%$.

house sparrow (from different localities) in one group with the American and Netherlands sparrows (bootstrapping $=69,72$ and 73, respectively). The Spain sample came basal to both groups. This relationship was trustable because of the reasonably strong statistical support. One cannot discriminate any intra-population variation for this bird in Saudi Arabia.

Nucleotide substitutions are generally considered in terms of transitions and transversions. The sequenced fragment of cytb gene showed 24 substitutions among the different haplotypes of which two were transversions. Among these polymorphic changes, 22 were in the third position, and 2 were in the first and second positions and therefore, 2 of these substitutions were non-synonymous and the 22 were synonymous. One of the non synonymous changes was found in only one haplotype from AlMadina and involved a substitution of phenylalanine with Sereine at T191 $\rightarrow$ C191. The position of this amino acid in the frame of cytb gene is at 64. The second substitution was found in different haplotypes inhabiting Qassim, Tabuk, Jazan and Taif and showed a transition for the amino acid number 116 from valine to isoleucine at A346 $\rightarrow$ G346 (Figure 3). It is notable that the non

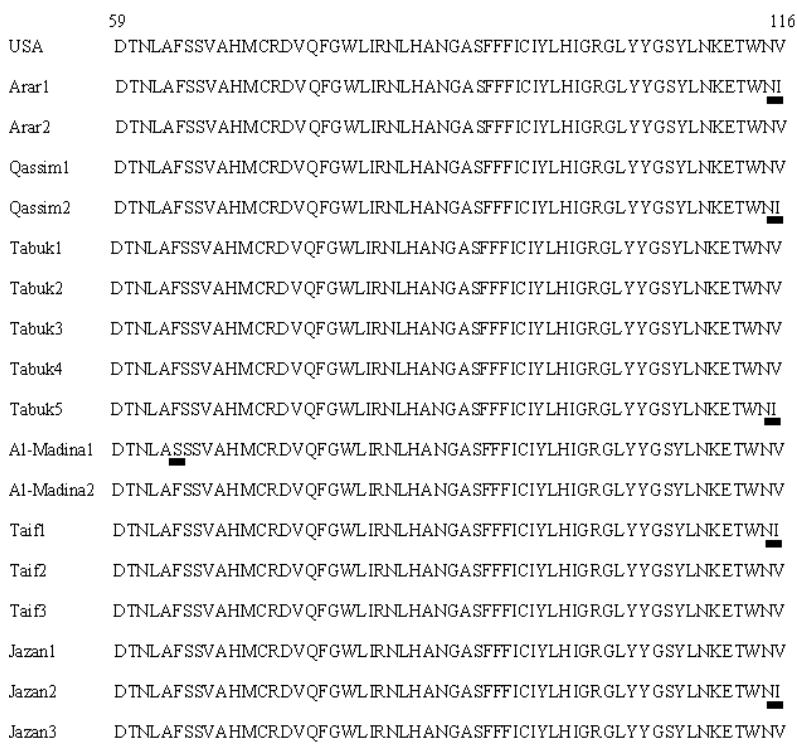

Figure 3. The aligned translated amino acids of the sequenced fragment of cytb gene for different haplotypes. The underlined letters are those amino acids with polymorphism. Note that this alignment is for the portion exhibited polymorphism (from 59 to 116$)$.

synonymous mutations were found in the samples inhabiting the localities at the vicinity of west Saudi Arabia, which is characterized by mountainous habitat. These habitats are acquired abundance of vegetations and characterized by different climate (temperature, rainfall and humidity). Further study is necessary in which more statistical packages for more samples and data should be used to relate these changes to ecology.

Due to their ability to fly, birds can move over large geographical scales, and their populations are therefore often spatially more homogeneous than in some other taxonomic groups $[4,19,20]$. The genetic variability within house sparrow populations in Saudi Arabia were in the same category as previously estimated for other areas in the world [9,11,21]. Genetic variability within its populations was very limited probably due to the connection between them [1]. We found a weak differenttiation among some of the populations, mainly in those at the western edge of the Kingdom, but other areas showed no significant population difference (Table 1). Accordingly, we could not differentiate any type of clusters of individuals within the collected data. Extensive homogeneity of populations was most likely due to populations are better connected. We, therefore, concluded that Saudi Arabian house sparrow needs collection of more samples and DNA data and manipulates these data by up to data statistical programs to address its genetic diversity.

\section{ACKNOWLEDGEMENTS}

This work has been done under the financial support of Taif Univer- 
sity of Kingdom of Saudi Arabia (Project number 1/432/1066).

\section{REFERENCES}

[1] Kekkonen, J., Seppa, P., Hanski, I.K., Jensen, H., Vaisanen, R.A. and Brommer, J.E. (2011) Low genetic differentiation in a sedentary bird: House sparrow population genetics in a contiguous landscape. Heredity, 106, 183-190. doi:10.1038/hdy.2010.32

[2] Summers-Smith, J.D. (1988) The Sparrows: A study of the genus passer. T and AD Poyser, Staffordshire.

[3] Anderson, T.R. (2006) The ubiquitous house sparrow: From genes to populations. Oxford University Press, Oxford. doi:10.1093/acprof:oso/9780195304114.001.0001

[4] Barrowclough, G.F. (1983) Biochemical studies of microevolutionary processes. In: Brush, A.H. and Clark. J.G.A. Eds., Perspectives in ornithology, University of Cambridge Press, Cambridge, 223-261.

[5] Fleischer, C. (1983) A comparison of theoretical and electrophoretic assessment of genetic structure in populations of the house sparrow (Passer domesticus). Evolution, 37, 1001-1009. doi:10.2307/2408414

[6] Parkin, D.T. and Cole, S.R. (1985) Genetic differentiation and rates of evolution in some populations of the house sparrow (Passer domesticus) in Australia and New Zealand. Heredity, 53, 15-23. doi:10.1038/hdy.1985.4

[7] Bjordal, H., Cole, S.R. and Parkin, D.T. (1986) Genetic differentiation among some populations of the house sparrow Passer domesticus from south-western Norway. Heriditas, 105, 107-114. doi:10.1111/j.1601-5223.1986.tb00648.x

[8] Wetton, J.H., Parkin, T. and Carter, R.E. (1992) The use of genetic markers for parentage analysis in Passer domesticus (house sparrows). Heredity, 69, 243-254. doi:10.1038/hdy.1992.122

[9] Neumann, K. and Wetton, J.H. (1996) Highly polymorphic microsatellites in the house sparrow Passer domesticus. Molecular Ecology, 5, 307-309. doi:10.1111/j.1365-294X.1996.tb00319.x

[10] Griffith, S.C., Stewart, I.R.K., Dawson, D.A., Owens, I.P.F. and Burke, T. (1999) Contrasting levels of extra-pair paternity in mainland and island populations of the house sparrow (Passer domesticus): Is there an "island effect”? Biological Journal of the Linnaean Society, 68, 303-316. doi:10.1006/bijl.1999.0343

[11] Griffith, S.C., Dawson, D.A., Jensen, H., Ockendon, N.,
Greig, C., Neumann, K. and Burke, T. (2007) Fourteen polymorphic microsatellite loci characterized in the house sparrow Passer domesticus (Passeridae, Aves). Molecular Ecology, 7, 333-336.

[12] Allende, L.M., Ruboi, I., Guillén, J., Ruiz-del-Valle, V., Guillen, J., Martinez-Laso, J. and Lowy, E. (2001) The old world sparrows (Genus Passer): Phylogeography and their relative abundance of nuclear mtDNA pseudogenes. Journal of Molecular Evolution, 53, 144-154.

[13] Van der Meij, M.A.A., de Bakker, M.A.G. and Bout, R.G. (2005) Phylogenetic relationships of finches and allies based on nuclear and mitochondrial DNA. Molecular Phylogenetics and Evolution, 34, 97-105. doi:10.1016/j.ympev.2004.09.006

[14] Dor, R. and Lotem, A. (2009) Heritability of nestling begging intensity in the house sparrow (Passer domesticus). Evolution, 63, 738-748. doi:10.1111/j.1558-5646.2008.00598.x

[15] Negro, J.J. and Torres, M.J. (1999) Genetic variability and differentiation of two bearded vulture Gypaetus barbatus populations and implications for reintroduction projects. Biological Conservation, 87, 249-254. doi:10.1016/S0006-3207(98)00056-1

[16] Edwards, S.V., Arctander, P. and Wilson, A.C. (1991) Mitochondrial resolution of a deep branch in the genealogical tree for perching birds. Proceedings: Biological Sciences, 243, 99-107. doi:10.1098/rspb.1991.0017

[17] Swofford, D.L. (2002) PAUP*. Phylogenetic analysis using parsimony (*and Other Methods). 4th Edition, Sunder-land, Sinauer.

[18] Saitou, N. and Nei, M. (1987) The neighbor-joining method: A new method for reconstructing phylogenetic trees. Molecular Biology and Evolution, 4, 406-425.

[19] Evans, P.G.H. (1987) Electrophoretic variability of gene products. In: Cooke, F. and Buckley, P.A. Eds., Avian genetics: A population and ecological approach, Academic Press, London, 105-162.

[20] Ward, R.D., Skibinski, D.O.F. and Woodwark, M. (1992) Protein heterozygosity, protein structure, and taxonomic differentiation. Evolutionary Biology, 26, 73-159. doi:10.1007/978-1-4615-3336-8_3

[21] Garnier, S., Durand, P., Arnathau, C., Risterucci, A.M., Esparza-Salas, R., Cellier-Holzem, E. and Sorci, G. (2009) New polymorphic microsatellite loci in the house sparrow, Passer domesticus. Molecular Ecology Resources, 9, 1063-1065. doi:10.1111/j.1755-0998.2009.02552.x 